\title{
The course of the acute vertebral body fragility fracture: its effect on pain, disability and quality of life during 12 months
}

\author{
Nobuyuki Suzuki · Osamu Ogikubo · \\ Tommy Hansson
}

Received: 28 April 2008/Revised: 24 June 2008 / Accepted: 3 August 2008 / Published online: 27 August 2008

(C) The Author(s) 2008. This article is published with open access at Springerlink.com

\begin{abstract}
The vertebral body fracture is the most frequent bone fragility fracture. In spite of this there is considerable uncertainty about the frequency, extent and severity of the acute pain and even more about the duration of pain, the magnitude of disability and how much daily life is disturbed in the post-fracture period. The aim of the present study was to follow the course of pain, disability, ADL and QoL in patients during the year after an acute low energy vertebral body fracture. The study design was a longitudinal cohort study with prospective data collection. All the patients over 40 years admitted to the emergency unit because of back pain with a radiologically acute vertebral body fracture were eligible. A total of 107 patients were followed for a year. The pain, disability (von Korff pain and disability scores), ADL (Hannover ADL score), and QoL (EQ-5D) were measured after 3 weeks, 3, 6 and 12 months. Two-thirds of the patients were women, and were similar in average age, as the men around 75 years. A total of $65.4 \%$ of the fractures were due to a level fall or a minor trauma, whereas $34.6 \%$ had no recollection of trauma or a specific event as the cause of the fracture. A total of $76.6 \%$ of the fractured patients were immediately
\end{abstract}

\footnotetext{
N. Suzuki · O. Ogikubo

Department of Orthopaedic Surgery,

Nagoya City University Graduate School of Medical Sciences,

1-Kawasumi, Mizuho-cho, Mizuho-ku, Nagoya,

Aichi 467-8601, Japan

T. Hansson $(\square)$

Department of Orthopaedics, Sahlgrenska Academy,

Gothenburg University, Bruna Stråket 11,

41345 Göteborg, Sweden

e-mail: tommy.hansson@orthop.gu.se
}

mobilized and allowed to return home while the remaining were hospitalized. The average pain intensity score after 3 weeks was 70.9 (SD 19.3), the disability score 68.9 (SD 23.6), the ADL score 37.7 (SD 22.1) and EQ-5D score of 0.37 (SD 0.37). The largest improvements, 10-15\%, occurred between the initial visit and the 3 months followup and were quite similar for all the measures. From 3 months, all the outcome measures leveled out or tended to deteriorate resulting in a mean pain intensity score of 60.5, disability score of 53.9, ADL score of 47.6, and EQ$5 \mathrm{D}$ score 0.52 after 12 months. After a whole year the fractured patients' condition was similar to the preoperative condition of patients with a herniated lumbar disc, central lumbar spinal stenosis or in patients $100 \%$ work disabled due to back or neck problems. Instead of the generally believed good prognosis for the greater majority of those fractured, the acute vertebral body fracture was the beginning of a long-lasting severe deterioration of their health.

Keywords Vertebral body fracture - Osteoporosis . Pain · Quality of life - Disability · Compression fracture

\section{Introduction}

The vertebral body fracture is the most frequent type of osteoporotic fracture [12]. Approximately 30-50\% of women and $20-30 \%$ of men develop vertebral fractures and half of them develop multiple fractures during their lifetime, compared with a $15.6 \%$ lifetime risk of a hip fracture [50]. The annual incidence rate of a vertebral body fracture in women over 50 years of age has been found to be 17.8 in 1,000 person-years [43]. In Sweden, a remarkable increase in incidence and prevalence for this 
type of fracture, especially among those of older age was noted between the 1950s and 1980s [6]. It is well known and frequently reported that the vertebral body fracture causes pain, disability and has a negative effect on the patient's health-related quality of life (QoL) $[2,8-10,13$, $15,19,20,30,34,39,41,46,49,51,53]$. Both pro- and retrospective data suggest that the deterioration of health after a vertebral fracture can last for many years and with sequel that usually are worse than for the other bone fragility fractures [29, 30, 34, 45]. It has also been noted that many patients, mainly women, with numerous fractures have never come to clinical attention [14, 22]. Socalled subclinical vertebral fractures have been found to exert only a moderate effect on the patient's QoL. Not surprisingly, it has likewise been noted that the time since the fracture occurred is of importance for the reported QoL, irrespective of age [1, 4, 9]. The most negative influence of subclinical fractures has been reported in the domains of pain, general health, and social and physical functioning $[3,38]$. The effect on QoL of the vertebral fracture was prospectively studied in two Swedish studies. These studies suggested that this fracture type had a more negative and long-lasting impact on the patient's QoL than any other type of osteoporotic fracture, including the hip fracture $[8,30]$.

Several different instruments for determining the effect on the QoL, such as SF-36, SF-12, or EQ-5D, have been used for patients with vertebral body fractures $[2,3,8,9$, $40,44,51,57]$.

In spite of the high incidence and prevalence of this fracture type, surprisingly little is known about its longterm course. Generally it has been believed that the problems related to this type of fracture are self-limiting. The pain after an acute vertebral compression fracture for example, has been reported as intense at the fracture site up to 4-6 weeks, and turning into chronic pain only in patients with multiple compression fractures, height loss, and low bone density [52]. It has also been reported that spontaneous pain, measured using a visual analog scale, did not decrease significantly until day 15 , but had decreased by approximately $40 \%$ when measured at day 30 [26]. Others have found that acute fracture pain decreased by $22 \%$ at day 7 , and by $33 \%$ at day 14 [42].

There is considerable uncertainty about the frequency, extent and severity of the acute pain and even more about the duration of pain, the magnitude of disability and how much daily life is disturbed in the post-fracture period.

Although several studies have evaluated large samples of patients with non acute vertebral fractures, the aim of the present study was to prospectively evaluate the course over 12 months of non-surgically treated acute vertebral compression fractures on pain, disability, ADL, and QoL.

\section{Materials and methods}

All patients over 40 years of age who were admitted to the emergency unit at Sahlgrenska University Hospital, Gothenburg, Sweden because of back pain and had a radiologically acute vertebral fracture which resulted from a low energy trauma were eligible for the study. Patients with an acute fracture in an earlier fractured spine were also included. The study was conducted from December 2003 to November 2006.

Excluded were those with any other type of acute fracture (forearm, hip etc.), fracture/fractures related to malignancy, infection or any other bone disease, except osteoporosis, that could affect the mechanical integrity of the vertebrae in the lumbar or thoracic spines. The presence or suspicion of more than one acute fracture excluded from the study.

Within 10 days after the visit to the hospital's emergency unit, all eligible patients received written information about the study and an invitation to participate. The patients who agreed to participate received a first questionnaire at the latest 3 weeks after the fracture had been diagnosed and then after 3, 6 and 12 months. The questionnaires were self explanatory and intended to be used for postal surveys. The patients returned the filled-in questionnaires which seemed to make later comparisons unlikely. The questionnaires described below were used in the study; all of the questionnaires were used at each of the four follow-up times.

\section{Questionnaires}

\section{von Korff pain intensity and disability questionnaires}

This instrument is self-administered and was designed and validated for use among patients with among others back pain outside the hospital setting $[55,56]$. It includes three pain intensity and four disability items. The three pain items ask the patient to rate the back pain intensity right now, the worst pain and the average pain since the start of the pain problem where 0 is "no pain" and 10 is "pain as bad could be". The Pain Intensity score is calculated as the average of the three $0-10$ ratings multiplied by 10 to yield a $0-100$ score. Three of the disability items also have a 10 -graded response possibility. One item is about the interference of the back pain on the daily activities ranging between 0 , "no interference" and 10, "unable to carry on any activities" and two are about how the back pain has changed the ability to take part in family, social or recreational activities, or the ability to work (including household) both ranging between 0 , "no change" and 10 , "extreme change". The fourth disability question asks about the number of days the subject, due to the pain, has 
been kept from the usual activities during the last 6 months. This fourth question is not used in this study. The Disability score is calculated as the average of three 0 10 interference ratings in daily, social and work activities multiplied by 10 to yield a $0-100$ score $[55,56]$. The scores have been used in several international and Swedish studies of long-term back pain [32] (see Appendix).

\section{Hannover ADL score}

This questionnaire is also self-administered and consists of 12 items. It assesses functional limitations in activities of daily living (ADL) among patients with musculoskeletal disorders. Item examples are; "Can you wash and dry yourself from head to toe?" and "Can you raise yourself from a lying position?" The response alternatives are three (circle one); 1. Either unable to do or able only with help ( score $=0), 2$. Yes, but with some difficulties (score $=1$ ), or 3. Yes, without difficulties (score $=2$ ). The 12 items are scored, summed and transformed on to a scale from 0 (worst back function) to 100 (best back function [37]. The questionnaire has been used in several international and Swedish studies of long-term back pain [32] (see Appendix).

\section{EQ-5D}

This is a generic health-related quality of life measure. It provides a single index. The individuals classify their own health status into five dimensions: mobility, self-care, usual activity, pain/discomfort and anxiety/depression within three levels (i.e. no problems, moderate problems and severe problems). The instrument yields a total of 243 possible health states, and the Time Trade Off method is used to rate the different states of health. The value 0 indicates "dead" and 1 indicates "full health" [16, 17]. Negative values are possible and represent conditions worse than dead. In Sweden, the instrument has been validated on extensive cohorts of back pain patients and of ages similar to those expected in the present study [11].

\section{Spinal radiographs}

Lateral and frontal view radiographs of the spine were taken at the first visit to the hospital's emergency unit, when there was a suspicion of an acute vertebral body fracture as the cause of the back pain. The presence of an acute fracture was primarily decided by the attending radiologist. For the purpose of the study, two experienced spine surgeons separately re-evaluated the radiographs. The acute vertebral body fracture was determined based on: (1) the existence of a fracture deformation compared with the normal neighboring vertebrae, (2) pain at or near the fracture deformation, (3) an evident sharp edge in the deformed region [5] and (4) no callus formation at the fractured vertebra [5]. The type of fracture was determined as wedge, concave, or crush [48] and the grade of fracture was assessed according to the emiquantitative method by Genant et al. [23-25]. In questionable cases, previous or subsequent imaging examinations e.g. MR were used to confirm or reject the presence of the acute fracture. In cases of divergent opinions, the cases were discussed and consensus reached.

\section{Preventive treatment}

A total of 14 of the 107 patients reported that they had taken medication during the year prior to the actual fracture to increase their bone mineral.

\section{Statistical analysis}

The SPSS statistical software program was used for analyzing the data.

Parametric tests, independent or paired $t$ tests were used for parametric scale variables. Differences between groups were analyzed with parametric methods. Nominal variables were tested using the Chi-square test. For comparison of repeated measurements, repeated ANOVA was used. If the repeated ANOVA was significant, the Bonferroni/Dunn procedure was used as a post hoc test. All tests were twosided. The results were considered to be significant at $P<0.05$.

\section{Ethical approval}

The study was ethically approved by the Research Ethical Committee of the Medical Faculty, Gothenburg University, 17 June 2003 (S 270-03).

\section{Results}

Study population

A total of 341 patients were invited to participate in the study. A total of 67 of those actively refused to participate due to old age and/or co-morbidities as the main reasons. A total of 122 patients did not respond to the invitation, thus were excluded. Five patients had died within the weeks after the fracture episode. A total of 147 patients accepted to participate. Among the 147 patients, 110 answered the questionnaires at all four of the follow-ups; 29 patients did not answer the 1 year follow-up questionnaires in spite of three reminders, and 8 patients died during the 1 year 
follow-up. Three of 110 patients underwent vertebroplasty during the follow-up period and were excluded. The final analysis included 107 patients followed for 1 year.

Due to internal missing data in the response to von Korff's disability score, six patients had to be excluded from the analysis of this particular instrument.

The average age for those refraining from participation, irrespective of reason, was 81.1 years (SD 13.2) which was older $(P<0.05)$ than for those included in the study. There was no difference between the proportion of women and men in the two groups $(P>0.05)$.

\section{Patient characteristics}

The characteristics of the patients included in this study are presented in Table 1. There was no age difference between men and women $(P>0.05)$. There was no difference at any time during the follow-up in any of the outcome measures between those with a known trauma causing the fracture (fall, lift, undefined trauma or traffic accident) and those without such a trauma or between the patients that after the fracture waited differently long before they visited the emergency unit. Better ADL and higher QoL after one year was found among the patients immediately returning home than among those hospitalized $(P<0.05)$.

\section{Fracture location}

The acute fractures diagnosed in this study were located between Th6 and L4, and were most frequent at the thoracolumbar junction (Fig. 1).

Pain, disability, ADL and Quality of life

The main outcome measures at 3 weeks, and 3, 6 and 12 months after the osteoporotic vertebral fracture are shown in Table 2 and Fig. 2.

von Korff pain intensity score

As can be seen in Fig. 2, the average pain intensity reduced during the first 3 months to just above $60(P<0.001)$ and remained at this rather high level even at the 1-year followup $(P>0.05)$. Through the follow-up, the women consistently reported more pain than the men, although the differences were statistically significant only at 3 months.

When the initial pain intensity for each individual was grouped into quartiles, 50 patients $(46.7 \%)$ belonged to the fourth quartile with a pain intensity between 75 and 100, 54 patients $(50.5 \%)$ belonged to the second and third quartiles and only 3 patients $(2.8 \%)$ to the lowest quartile with a pain intensity less than 25 (Fig. 3). The biggest shift in pain
Table 1 Baseline characteristics of the patients included in this study

\begin{tabular}{ll}
\hline Patient characteristic & \\
\hline Total population & 107 \\
Age, mean \pm SD (range) & $75.5 \pm 11.9(42-96)$ \\
Gender & \\
Female (\%), age mean \pm SD (range) & $72(67.3), 75.3 \pm 12.3$ (42-96) \\
Male (\%), age mean \pm SD (range) & $35(32.7), 76.1 \pm 11.2(43-92)$ \\
Cause of trauma & \\
A level fall $(\%)$ & $62(57.9)$ \\
Lift of a heavy object $(\%)$ & $2(1.9)$ \\
Unidentified trauma $(\%)$ & $2(1.9)$ \\
Traffic accident $(\%)$ & $4(3.7)$ \\
No recollection of trauma (\%) & $37(34.6)$ \\
Time elapsed before visiting the emergency unit & \\
Within the first week $(\%)$ & $72(67.3)$ \\
Within 1 month $(\%)$ & $16(14.9)$ \\
Unidentified (\%) & $19(17.8)$ \\
Post fracture status & \\
Immediate return home $(\%)$ & $82(76.6)$ \\
Hospitalized (\%) & $23(21.5)$ \\
Nursing home $(\%)$ & $2(1.9)$ \\
Days in hospital, mean \pm SD (range) & $16.7 \pm 8.1(3-35)$ \\
Brace prescription $(\%)$ & $12(11.2)$ \\
\hline
\end{tabular}


Fig. 1 The location of the fracture in the 107 patients

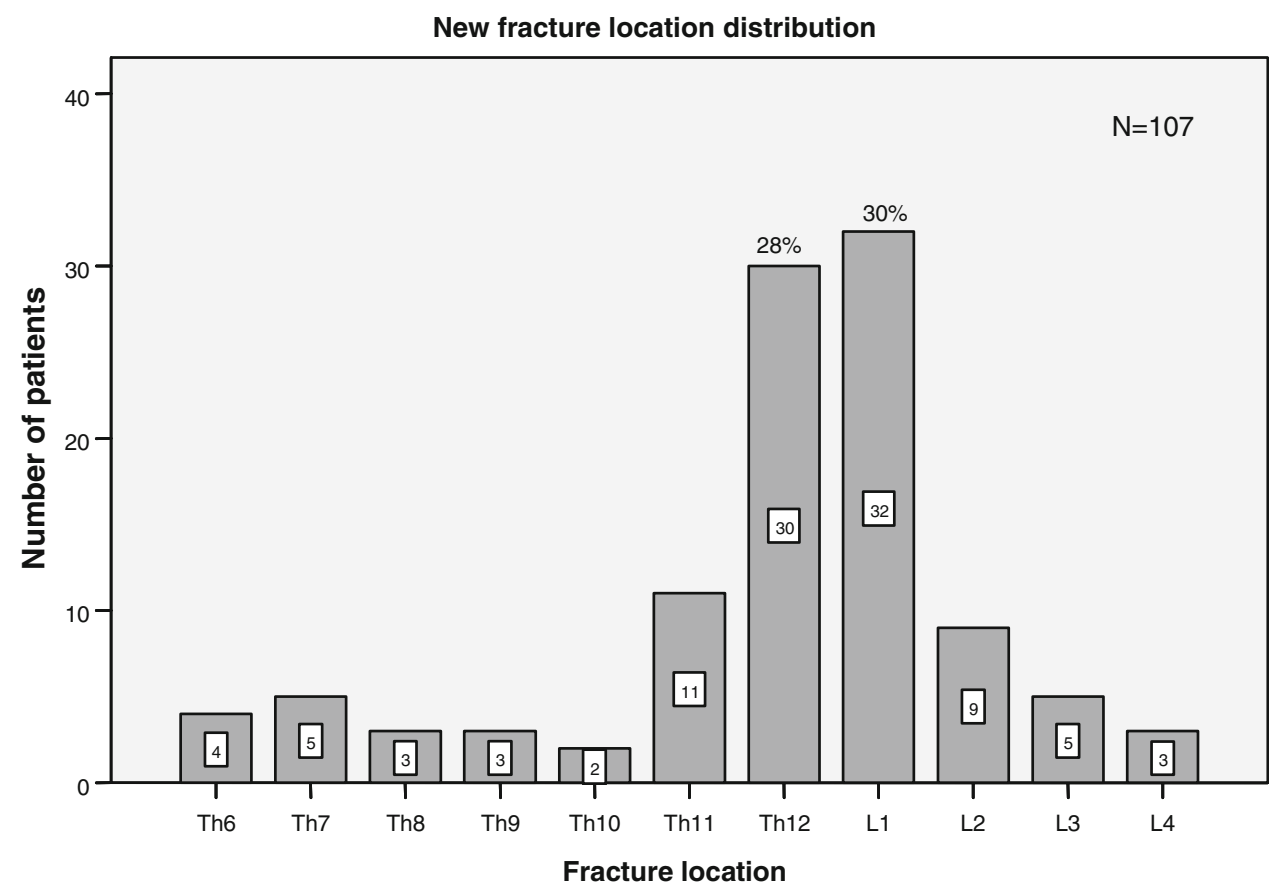

Table 2 The results of the four questionnaires at the follow-ups ( 3 weeks, 3, 6 and 12 months)

\begin{tabular}{|c|c|c|c|c|c|c|c|c|}
\hline & \multicolumn{2}{|c|}{3 weeks } & \multicolumn{2}{|c|}{3 months } & \multicolumn{2}{|c|}{6 months } & \multicolumn{2}{|c|}{12 months } \\
\hline & Mean & SD & Mean & $\mathrm{SD}(P)$ & Mean & $\mathrm{SD}(P)$ & Mean & $\mathrm{SD}(P)$ \\
\hline von Korff pain intensity score & 70.9 & 19.3 & 61.5 & $21.4(0.000)$ & 60.7 & $21.6(0.000)$ & 60.5 & $23.0(0.000)$ \\
\hline von Korff disability score & 68.9 & 23.6 & 56.4 & $25.5(0.000)$ & 51.0 & $27.5(0.000)$ & 53.9 & $27.8(0.000)$ \\
\hline Hannover ADL score & 37.7 & 22.1 & 48.0 & $25.0(0.000)$ & 45.8 & $26.3(0.000)$ & 47.6 & $26.4(0.000)$ \\
\hline EQ-5D & 0.37 & 0.37 & 0.52 & $0.35(0.000)$ & 0.54 & $0.36(0.000)$ & 0.52 & $0.38(0.000)$ \\
\hline
\end{tabular}

$P$ values are given for differences between 3, 6 and 12 months and baseline (3 weeks)

intensity between the acute state and the 3-month followup was among those in the highest quartile (worst pain). After 12 months, less than $10 \%$ of the patients had a pain intensity below 25 , while 81 patients $(75.7 \%)$ still experienced a pain intensity over 50 .

\section{von Korff disability score}

Disability like pain intensity showed the largest improvement between 3 weeks and 3 months but unlike pain intensity the disability score continued to improve until 6 months $(P<0.021)$ (Fig. 2).

\section{Hannover ADL score}

Hannover ADL score improved with more than ten units between the first and second follow-ups $(P<0.000)$. Except for the 6-month follow-up the men reported statistically significant better ADL than the women $(P<0.05)$.

\section{EQ-5D}

Initially, average quality of life, as measured using EQ$5 \mathrm{D}$, for all patients was 0.37 (SD 0.37). In comparison to this initial value, improvement was shown at all three subsequent follow-ups $(P<0.000)$. Even if improved the EQ-5D remained low after 3 months with an average value of 0.52 (SD 0.38) at the 1-year follow-up. The gender-differentiated quality of life paralleled each other to a great extent, but with a statistically significant higher value for the men only after 3 months $(P<0.041)$. Except among those younger than 70 years of age, the EQ-5D values tended to deteriorate at the 6 and 12 months follow-ups.

When EQ-5D was divided into five dimensions (mobility, self-care, usual activity, pain/discomfort, and anxiety/depression) and analyze the percentage of the patients who had moderate or severe problem, the pain/ discomfort was the most dominant deteriorated dimension (Fig. 4). 


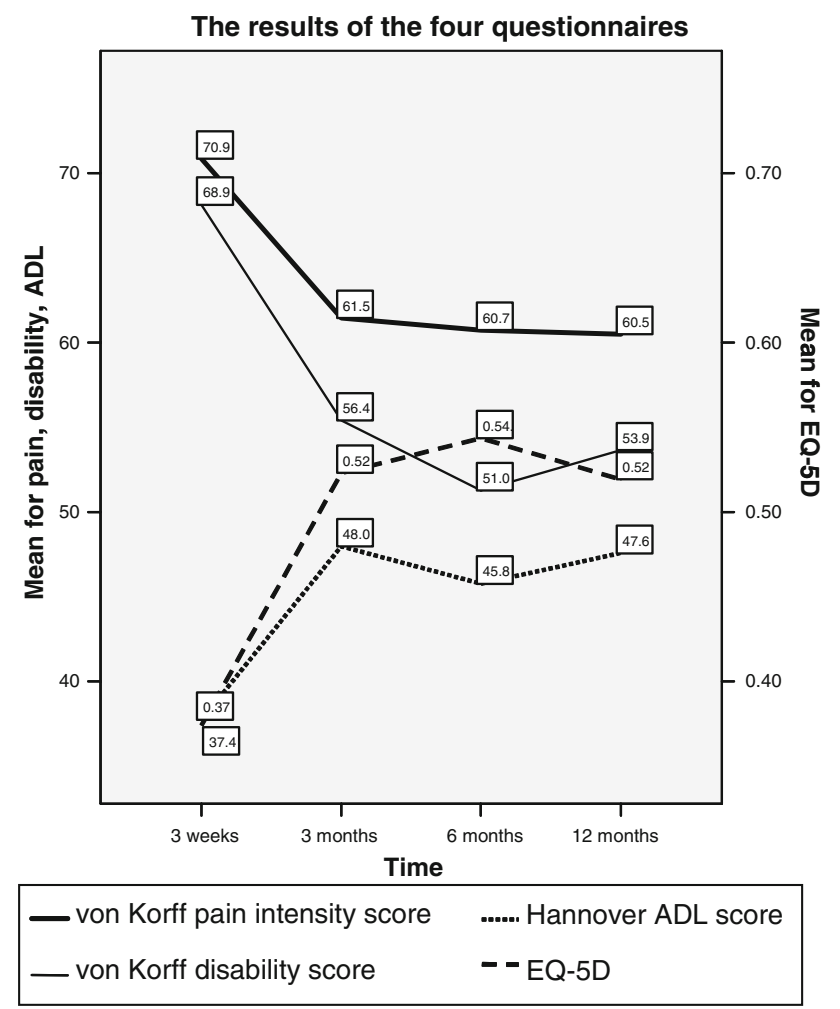

Fig. 2 The average pain intensity, disability, ADL, and QoL acutely and after 3, 6 and 12 months for all participants

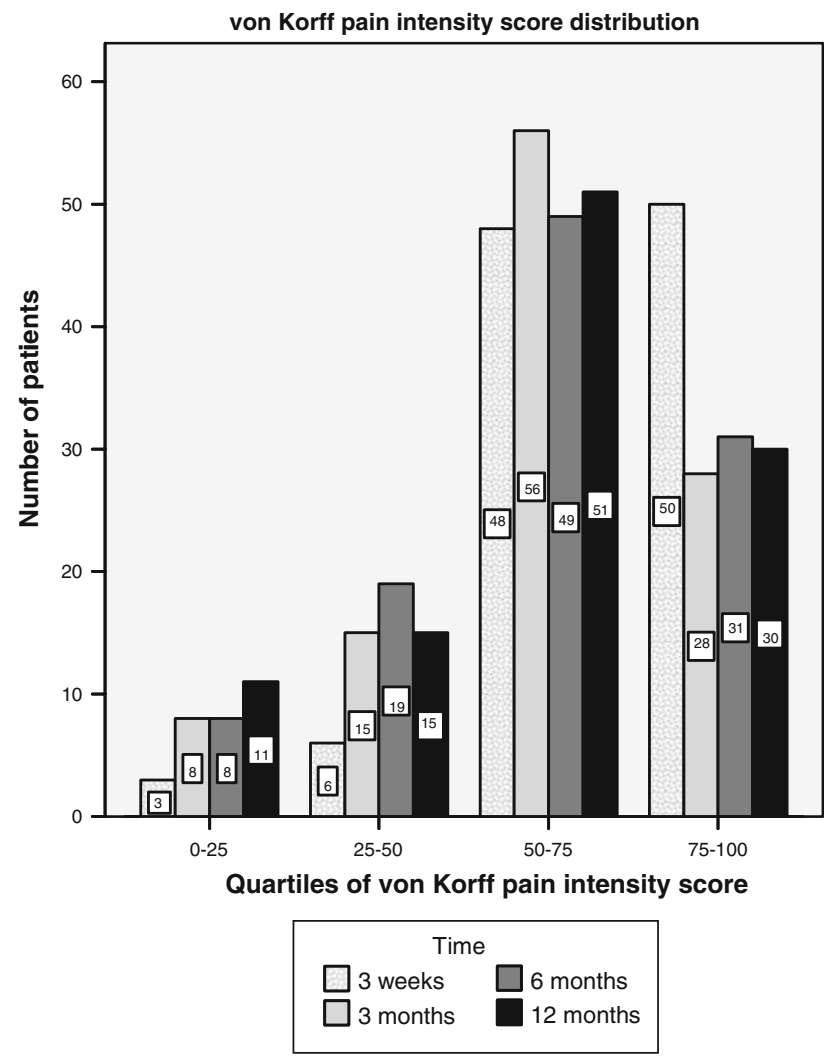

Fig. 3 The patient's pain intensity distributed into quartiles at the four follow-ups

\section{Discussion}

The problems accompanying a vertebral body fracture are generally regarded as self-limiting within weeks or a few months and as having a good prognosis, at least for the majority of the fractured [47, 52]. The results of the present study revealed a contrasting view. By following individual patients from the fracture occurrence and up to 1 year, it was found that this fracture was the starting point of a longlasting painful and disabling health condition that strongly reduced the patient's health-related quality of life. Since the large majority of the cohort members received nothing but symptomatic pain medication, general mobilization, and activity recommendations, it is reasonable to assume that the current findings closely represent the natural course of an acute vertebral body fracture.

\section{Pain}

The initial pain intensity recorded 2-3 weeks after the occurrence of the fracture was lowered during the first 3 months, but remained on a high level for the rest of the 1-year follow-up. The initial average pain intensity, as measured with von Korff's pain intensity score was high and reflected to some extent the initial fracture pain (70.9, SD 19.3). The pain intensity after 6 months and 1 year remained at a high level. It was of the same magnitude as the average pain intensity in a Swedish cohort of men and women who were fully work disabled for more than 3 months due to back [32]. Although not directly transferable, the pain intensity after a whole year in the fractured patients (average 60.5) was just as severe as the preoperative pain in the patients included in the Swedish National Spine Register subsequently undergoing surgery for lumbar disc herniation (VAS: back 45, leg 64) or central spinal stenosis (VAS: back 55, leg 61) [54]. It has been argued that $84 \%$ of clinically diagnosed fractures are associated with pain and that around half of those with a radiologically identified fracture have any symptoms [50, 52]. The present study showed that more than $97 \%$ reported a pain intensity of a severity that usually is regarded as clinically significant (Fig. 3). Since pain most likely was the main reason for visiting the emergency unit, it is likely that all the patients experienced acute pain in direct relation to the fracture and probably also more pain than what was reported in the first questionnaire administered 2-3 weeks after the occurrence of the fracture. After 1 year, only around $10 \%$ reported no or very little pain while almost $76 \%$ still had pain intensity regarded as severe (Fig. 3). From a pain aspect, the current results revealed a situation much worse and more frequent than indicated before [50]. 
Fig. 4 The frequency of those reporting moderate or severe problems in the five dimensions of EQ-5D at the four follow-ups

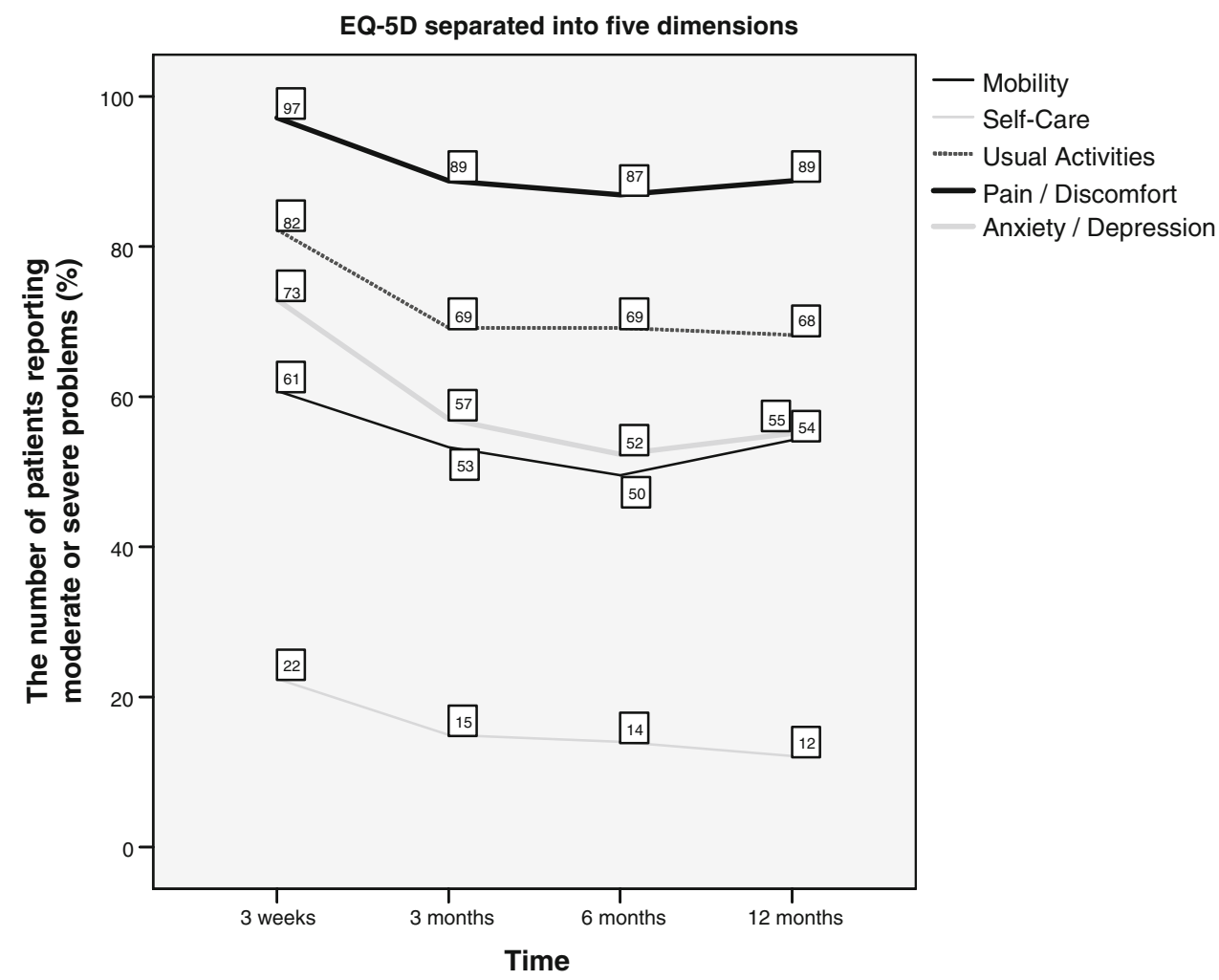

In the US one-third of all the annually estimated 700,000 osteoporotic vertebral body compression fractures are believed to develop chronic pain [47]. The findings in the present study suggest that more than $3 / 4$ acquire severe pain, lasting at least 1 year after this type of fracture. This finding is corroborated by another Swedish study where it was noted that in more than $70 \%$ of the women, the occurrence of a vertebral body fracture was the beginning of a painful condition that could last at least up to 22 years [34].

\section{Disability and ADL}

The patient's disability rating pattern was quite similar to that for pain. In comparison to age-matched patients with non-osteoporotic chronic low back pain, it was found that the disability was greater among those with a vertebral fracture [38]. In the present study, considerably lower values (worse) for disability and ADL were noted at all follow-ups in comparison to large cohorts of patients from six different countries with disabling low back pain [32]. When the impairment after a vertebral fracture was analyzed in 1,010 women 6 years after the fracture, it was found that those with a previous fracture had up to seven times greater odds of reporting difficulties with a variety of activities than those without [28]. Similarly, it was noted that the odds of impaired ADL (defined as problems with $\geq 3$ physical or instrumental ADLs) were 2.3 times higher among those with an earlier clinically diagnosed vertebral fracture [18]. It has also been found that impairment of ADL does not have to be related to the presence of pain, particularly not in patients with two or more prevalent fractures [36].

EQ-5D

The initial QoL, measured with EQ-5D, was quite low and similar or worse than what has been noted for long-lasting disabling low back and neck pain and comparable to the preoperative levels for both a lumbar herniated disc and central spinal stenosis $[32,35,54]$. In a wider context than problems of the spine, the 3, 6 and 12-month EQ-5D values among the fractured patients found in the present study were similar or lower than the values found preoperatively in patients with hip and knee osteoarthritis, undergoing subsequent total joint replacement [31]. In comparison to the average EQ-5D value of 0.52 reported 1 year after the fracture in the present cohort, the corresponding values in hip fracture patients 1 year after total hip replacement surgery was 0.73 and after internal fixation surgery was 0.63 [7]. The EQ-5D values in the population of the city of Stockholm for the age groups 
represented in this study have been found to be just above 0.80 [11].

The worsening trend between 6 and 12 months was noticeable not only in the quality of life recordings, but also for pain and disability as well, and seemed to emphasize the profound negative and lasting effect of this fracture [46]. In another Swedish cohort study, it was noted that all of the SF-36 dimensions were significantly lowered, even 2 years after a vertebral body fracture, which was worse than after a hip fracture [30].

\section{Treatment}

The findings in the present study revealed that the treatment strategy which recommended as normal and early physical activity as possible seemed to have quite questionable positive effects. Presently we do not know whether strict or partial immobilization of the fractured spine is a more adequate treatment or not. In two Japanese studies, it has been suggested that in order to prevent collapse, deformity and lasting pain, the acute fracture must be diagnosed early and treated with a rigid external fixation, e.g. a hard brace or a body cast $[21,58]$. At the same time, it is well understood that there is a need for early mobilization since bed rest and inactivity more or less inescapably will lead to muscle waste and rapid bone mineral loss from the already fragile vertebrae [27, 33]. The unsatisfactory long-term prognosis for the great majority of patients with a vertebral fracture suggest that the reportedly successful pain-relieving interventions like vertebro- and kyphoplasty can possibly be employed on a much wider scale.

\section{Limitations}

\section{Accuracy of X-ray assessment}

The assessment of prevalent or incident vertebral fractures from spinal radiographs is sometimes quite difficult. In cases with minimal fracture deformation, there is frequent disagreement about whether a fracture is present or not. Some of the difficulties are the result of the variations in shape from one vertebra to another and also between individuals. To distinguish whether a fracture is incident or prevalent can be even more complicated, especially for patients with severe osteoporosis and multiple compression fractures. Some patients who present with back pain of sudden onset are erroneously diagnosed as having acute vertebral fractures when in fact the deformity has been present on earlier films [50].
Since an acute fracture in the present study was determined through clinical signs and plain X-rays, it is a risk that some fractures interpreted as acute might rather have been relatively old.

Another explanation for the presence of relatively old "new" fractures was the fact that almost $17.8 \%$ of the patients in the study had their fracture diagnosed 1 month or more after the fracture occurred (Table 1).

Since, in most cases, only one X-ray examination was evaluated it is possible that new fractures during the study year could have contributed to the problems during the post-fracture year.

\section{Lack of controls and old age}

Only the post-fracture situation is known. For this reason it is possible that some of the patients due to co-morbidity, for example, had an already deteriorated health-related quality of life subsequently made worse by the new fracture. The study did not include any controls without a spinal fracture. That is to some extent compensated by the fact that the scores used e.g. EQ-5D and Hannover ADL have age stratified population data.

The most important reason for the high number of non responders was old age. Since this fracture type especially involves older patients, this apparent weakness of the study is hard to overcome.

\section{Conclusions}

Hitherto, the vertebral fragility fracture generally has been regarded as a condition with self-limiting problems and as having a relatively positive prognosis. This study revealed, on the contrary that the vertebral fragility fracture has a severe impact on pain, disability, ADL, and QoL and that the fracture is the beginning of a deterioration of the patients health lasting at least for a year.

Acknowledgments The study was supported by grants from The Swedish Council for Working Life and Social Research, AFA Insurance, Sahlgrenska academy at Gothenburg University. The study was made possible through the cooperation with the Department of Orthopaedic Surgery, Nagoya City University, Nagoya Japan and its chairman professor Takanobu Otsuka.

Open Access This article is distributed under the terms of the Creative Commons Attribution Noncommercial License which permits any noncommercial use, distribution, and reproduction in any medium, provided the original author(s) and source are credited. 


\section{Appendix 1: von Korff pain intensity and disability score}

\section{von Korff pain intensity and disability score}

\section{Pain intensity items}

(1) How would you rate your pain right now? [Current pain]

\begin{tabular}{llllllllll} 
No pain & & & \multicolumn{4}{c}{ Pain as bad could be } \\
0 & 1 & 2 & 3 & 4 & 5 & 6 & 7 & 8 & 9
\end{tabular}

(2) After the fracture-how intense was your worst pain? [Worst Pain]

\begin{tabular}{llllllll} 
No pain & & & & & \multicolumn{4}{c}{$\begin{array}{c}\text { Pain as bad could be } \\
0\end{array}$} & 1 & 2 & 3 & 4 & 5 & 6 & 7 & 8 & 9
\end{tabular}

(3) After the fracture-how intense was your pain at an average? (That is, your usual pain at times you were experiencing pain.) [Average Pain]

\begin{tabular}{llllllllll} 
No pain & & & & & & \multicolumn{4}{c}{ Pain as bad could be } \\
0 & 1 & 2 & 3 & 4 & 5 & 6 & 7 & 8 & 9
\end{tabular}

\section{Disability items}

(4) After the fracture, how much has the pain interfered with your daily activities? [Daily Activities]

No interference Unable to carry on any activities

$\begin{array}{lllllllllll}0 & 1 & 2 & 3 & 4 & 5 & 6 & 7 & 8 & 9 & 10\end{array}$

(5) After the fracture, how much has the pain changed your ability to take part in recreational, social and family activities? [Social Activities]
No change
0
2
3
4

5
6
Extreme change

(6) After the fracture, how much has the pain changed your ability to work (including housework)? [Work Activities]
No change
$0 \quad 1$

23

the pain 
12. Can you run $100 \mathrm{~m}$ fast without stopping in order to catch a bus?

Those questions were answered by following score.

0. Either unable to do or able only with help.

1. Yes, but with some difficulties.

2. Yes, without difficulties.

Hannover ADL score $=($ total score $) /(2 \times($ number of valid answers) $) \times 100$.

\section{References}

1. Adachi JD, Ioannidis G, Olszynski WP, Brown JP, Hanley DA, Sebaldt RJ et al (2002) The impact of incident vertebral and nonvertebral fractures on health related quality of life in postmenopausal women. BMC Musculoskelet Disord 3:11. doi:10.1186/ 1471-2474-3-11

2. Adachi JD, Ioannidis G, Pickard L, Berger C, Prior JC, Joseph $\mathrm{L}$ et al (2003) The association between osteoporotic fractures and health-related quality of life as measured by the Health Utilities Index in the Canadian Multicentre Osteoporosis Study (CaMos). Osteoporos Int 14:895-904. doi:10.1007/s00198-0031483-3

3. Alekna V, Tamulaitiene M, Butenaite V (2006) The impact of subclinical vertebral fractures on health-related quality of life in women with osteoporosis. Medicina (Kaunas) 42:744-750

4. Begerow B, Pfeifer M, Pospeschill M, Scholz M, Schlotthauer T, Lazarescu A et al (1999) Time since vertebral fracture: an important variable concerning quality of life in patients with postmenopausal osteoporosis. Osteoporos Int 10:26-33. doi: 10.1007/s001980050190

5. Bengner U, Johnell O, Redlund-Johnell I (1988) Changes in incidence and prevalence of vertebral fractures during 30 years. Calcif Tissue Int 42:293-296. doi:10.1007/BF02556362

6. Bengner U, Johnell O, Redlund-Johnell I (1988) Changes in the incidence of fracture of the upper end of the humerus during a 30year period. A study of 2125 fractures. Clin Orthop Relat Res 231:179-182

7. Blomfeldt R, Tornkvist H, Ponzer S, Soderqvist A, Tidermark J (2005) Comparison of internal fixation with total hip replacement for displaced femoral neck fractures. Randomized, controlled trial performed at four years. J Bone Joint Surg Am 87:1680 1688. doi:87/8/1680[pii]10.2106/JBJS.D.02655

8. Borgstrom F, Zethraeus N, Johnell O, Lidgren L, Ponzer S, Svensson O et al (2006) Costs and quality of life associated with osteoporosis-related fractures in Sweden. Osteoporos Int 17:637650. doi:10.1007/s00198-005-0015-8

9. Brenneman SK, Barrett-Connor E, Sajjan S, Markson LE, Siris ES (2006) Impact of recent fracture on health-related quality of life in postmenopausal women. J Bone Miner Res 21:809-816. doi:10.1359/jbmr.060301

10. Burger H, Van Daele PL, Grashuis K, Hofman A, Grobbee DE, Schutte HE et al (1997) Vertebral deformities and functional impairment in men and women. J Bone Miner Res 12:152-157. doi:10.1359/jbmr.1997.12.1.152

11. Burstrom K, Johannesson M, Rehnberg C (2007) Deteriorating health status in Stockholm 1998-2002: results from repeated population surveys using the EQ-5D. Qual Life Res 16:15471553. doi:10.1007/s11136-007-9243-Z

12. Cauley JA, Hochberg MC, Lui LY, Palermo L, Ensrud KE, Hillier TA et al (2007) Long-term risk of incident vertebral fractures. JAMA 298:2761-2767. doi:10.1001/jama.298.23.2761
13. Cockerill W, Lunt M, Silman AJ, Cooper C, Lips P, Bhalla AK et al (2004) Health-related quality of life and radiographic vertebral fracture. Osteoporos Int 15:113-119. doi:10.1007/ s00198-003-1547-4

14. Cooper C, Atkinson EJ, O'Fallon WM, Melton LJ 3rd (1992) Incidence of clinically diagnosed vertebral fractures: a population-based study in Rochester, Minnesota, 1985-1989. J Bone Miner Res 7:221-227

15. Crans GG, Silverman SL, Genant HK, Glass EV, Krege JH (2004) Association of severe vertebral fractures with reduced quality of life: reduction in the incidence of severe vertebral fractures by teriparatide. Arthritis Rheum 50:4028-4034. doi: 10.1002/art.20671

16. Dolan P, Gudex C, Kind P, Williams A (1996) The time trade-off method: results from a general population study. Health Econ 5:141-154. doi:10.1002/(SICI)1099-1050(199603)5:2<141:: AID-HEC189>3.0.CO;2-N[pii]

17. Dolan P, Gudex C, Kind P, Williams A (1996) Valuing health states: a comparison of methods. J Health Econ 15:209-231. doi: 0167-6296(95)00038-0[pii]

18. Ensrud KE, Nevitt MC, Yunis C, Cauley JA, Seeley DG, Fox KM et al (1994) Correlates of impaired function in older women. J Am Geriatr Soc 42:481-489

19. Ettinger B, Black DM, Nevitt MC, Rundle AC, Cauley JA, Cummings SR et al (1992) Contribution of vertebral deformities to chronic back pain and disability. The Study of Osteoporotic Fractures Research Group. J Bone Miner Res 7:449-456

20. Fechtenbaum J, Cropet C, Kolta S, Horlait S, Orcel P, Roux C (2005) The severity of vertebral fractures and health-related quality of life in osteoporotic postmenopausal women. Osteoporos Int 16:2175-2179. doi:10.1007/s00198-005-2023-0

21. Fukuda F (2006) Importance of early diagnosis and early treatment for the conservative treatment of vertebral compression fracture in elderly people (Japanese). Mon Book Orthop 19:153159

22. Gallacher SJ, Gallagher AP, McQuillian C, Mitchell PJ, Dixon T (2007) The prevalence of vertebral fracture amongst patients presenting with non-vertebral fractures. Osteoporos Int 18:185192. doi:10.1007/s00198-006-0211-1

23. Genant HK, Jergas M (2003) Assessment of prevalent and incident vertebral fractures in osteoporosis research. Osteoporos Int 14(Suppl 3):S43-S55. doi:10.1007/s00198-002-1348-1,10.1007/ s00198-003-1472-6

24. Genant HK, Jergas M, Palermo L, Nevitt M, Valentin RS, Black $\mathrm{D}$ et al (1996) Comparison of semiquantitative visual and quantitative morphometric assessment of prevalent and incident vertebral fractures in osteoporosis. The Study of Osteoporotic Fractures Research Group. J Bone Miner Res 11:984-996

25. Genant HK, Wu CY, van Kuijk C, Nevitt MC (1993) Vertebral fracture assessment using a semiquantitative technique. J Bone Miner Res 8:1137-1148

26. Gennari C, Agnusdei D, Camporeale A (1991) Use of calcitonin in the treatment of bone pain associated with osteoporosis. Calcif Tissue Int 49(Suppl 2):S9-S13. doi:10.1007/BF02561370

27. Gold DT (1996) The clinical impact of vertebral fractures: quality of life in women with osteoporosis. Bone 18:185S-189S. doi: 10.1016/8756-3282(95)00500-5

28. Greendale GA, Barrett-Connor E, Ingles S, Haile R (1995) Late physical and functional effects of osteoporotic fracture in women: the Rancho Bernardo Study. J Am Geriatr Soc 43:955-961

29. Hall SE, Criddle RA, Comito TL, Prince RL (1999) A casecontrol study of quality of life and functional impairment in women with long-standing vertebral osteoporotic fracture. Osteoporos Int 9:508-515. doi:10.1007/s001980050178

30. Hallberg I, Rosenqvist AM, Kartous L, Lofman O, Wahlstrom O, Toss G (2004) Health-related quality of life after osteoporotic 
fractures. Osteoporos Int 15:834-841. doi:10.1007/s00198-0041622-5

31. Hansson T, Hansson E, Malchau H (2008) The utility of spine surgery. A comparison of common elective orthopaedic surgical procedures. Accepted in Spine

32. Hansson TH, Hansson EK (2000) The effects of common medical interventions on pain, back function, and work resumption in patients with chronic low back pain: a prospective 2-year cohort study in six countries. Spine 25:3055-3064. doi:10.1097/ 00007632-200012010-00013

33. Hansson TH, Roos BO, Nachemson A (1975) Development of osteopenia in the fourth lumbar vertebra during prolonged bed rest after operation for scoliosis. Acta Orthop Scand 46:621-630

34. Hasserius R, Karlsson MK, Jonsson B, Redlund-Johnell I, Johnell O (2005) Long-term morbidity and mortality after a clinically diagnosed vertebral fracture in the elderly-a 12- and 22-year follow-up of 257 patients. Calcif Tissue Int 76:235-242. doi: 10.1007/s00223-004-2222-2

35. Jansson KA, Nemeth G, Granath F, Jonsson B, Blomqvist P (2005) Health-related quality of life in patients before and after surgery for a herniated lumbar disc. J Bone Joint Surg Br 87:959_ 964. doi:10.1302/0301-620X.87B7.16240

36. Jinbayashi H, Aoyagi K, Ross PD, Ito M, Shindo H, Takemoto T (2002) Prevalence of vertebral deformity and its associations with physical impairment among Japanese women: The Hizen-Oshima Study. Osteoporos Int 13:723-730. doi:10.1007/s001980200099

37. Kohlmann T, Raspe H (1996) Hannover Functional Questionnaire in ambulatory diagnosis of functional disability caused by backache. Rehabilitation (Stuttg) 35: I-VIII

38. Leidig-Bruckner G, Minne HW, Schlaich C, Wagner G, ScheidtNave C, Bruckner T et al (1997) Clinical grading of spinal osteoporosis: quality of life components and spinal deformity in women with chronic low back pain and women with vertebral osteoporosis. J Bone Miner Res 12:663-675. doi:10.1359/jbmr. 1997.12.4.663

39. Leidig G, Minne HW, Sauer P, Wuster C, Wuster J, Lojen M et al (1990) A study of complaints and their relation to vertebral destruction in patients with osteoporosis. Bone Miner 8:217-229. doi:10.1016/0169-6009(90)90107-Q

40. Lips P, Cooper C, Agnusdei D, Caulin F, Egger P, Johnell O et al (1999) Quality of life in patients with vertebral fractures: validation of the Quality of Life Questionnaire of the European Foundation for Osteoporosis (QUALEFFO). Working Party for Quality of Life of the European Foundation for Osteoporosis. Osteoporos Int 10:150-160. doi:10.1007/s001980050210

41. Lyles KW, Gold DT, Shipp KM, Pieper CF, Martinez S, Mulhausen PL (1993) Association of osteoporotic vertebral compression fractures with impaired functional status. Am J Med 94:595-601. doi:10.1016/0002-9343(93)90210-G

42. Lyritis GP, Mayasis B, Tsakalakos N, Lambropoulos A, Gazi S, Karachalios T et al (1989) The natural history of the osteoporotic vertebral fracture. Clin Rheumatol 8(Suppl 2):66-69. doi: 10.1007/BF02207237

43. Melton LJ 3rd, Lane AW, Cooper C, Eastell R, O'Fallon WM, Riggs BL (1993) Prevalence and incidence of vertebral deformities. Osteoporos Int 3:113-119. doi:10.1007/BF01623271

44. Miyakoshi N, Hongo M, Maekawa S, Ishikawa Y, Shimada Y, Itoi E (2007) Back extensor strength and lumbar spinal mobility are predictors of quality of life in patients with postmenopausal osteoporosis. Osteoporos Int 18:1397-1403. doi:10.1007/s00198007-0383-3

45. O'Neill TW, Cockerill W, Matthis C, Raspe HH, Lunt M, Cooper $\mathrm{C}$ et al (2004) Back pain, disability, and radiographic vertebral fracture in European women: a prospective study. Osteoporos Int 15:760-765. doi:10.1007/s00198-004-1615-4

46. Oleksik AM, Ewing S, Shen W, van Schoor NM, Lips P (2005) Impact of incident vertebral fractures on health related quality of life (HRQOL) in postmenopausal women with prevalent vertebral fractures. Osteoporos Int 16:861-870. doi:10.1007/s00198-0041774-3

47. Phillips FM (2003) Minimally invasive treatments of osteoporotic vertebral compression fractures. Spine 28:S45-S53. doi: 10.1097/00007632-200308011-00009

48. Rao RD, Singrakhia MD (2003) Painful osteoporotic vertebral fracture. Pathogenesis, evaluation, and roles of vertebroplasty and kyphoplasty in its management. J Bone Joint Surg Am 85A:2010-2022

49. Romagnoli E, Carnevale V, Nofroni I, D’Erasmo E, Paglia F, De Geronimo S et al (2004) Quality of life in ambulatory postmenopausal women: the impact of reduced bone mineral density and subclinical vertebral fractures. Osteoporos Int 15:975-980. doi: 10.1007/s00198-004-1633-2

50. Ross PD (1997) Clinical consequences of vertebral fractures. Am J Med 103:30S-42S. doi:10.1016/S0002-9343(97)90025-5 Discussion $42 \mathrm{~S}-43 \mathrm{~S}$

51. Salaffi F, Cimmino MA, Malavolta N, Carotti M, Di Matteo L, Scendoni $\mathrm{P}$ et al (2007) The burden of prevalent fractures on health-related quality of life in postmenopausal women with osteoporosis: the IMOF study. J Rheumatol 34:1551-1560

52. Silverman SL (1992) The clinical consequences of vertebral compression fracture. Bone 13(Suppl 2):S27-S31. doi:10.1016/ 8756-3282(92)90193-Z

53. Silverman SL, Minshall ME, Shen W, Harper KD, Xie S (2001) The relationship of health-related quality of life to prevalent and incident vertebral fractures in postmenopausal women with osteoporosis: results from the multiple outcomes of Raloxifene Evaluation Study. Arthritis Rheum 44:2611-2619. doi:10.1002/ 1529-0131(200111)44:11<2611::AID-ART441>3.0.CO;2-N

54. Stromqvist B, Fritzell P, Hagg O, Jonsson B (2005) One-year report from the Swedish National Spine Register. Swedish Society of Spinal Surgeons. Acta Orthop Suppl 76:1-24. doi: Q62033144112T105[pii]10.1080/17453690510041950

55. Von Korff M, Deyo RA, Cherkin D, Barlow W (1993) Back pain in primary care. Outcomes at 1 year. Spine 18:855-862. doi:10.1097/00007632-199306000-00008

56. Von Korff M, Ormel J, Keefe FJ, Dworkin SF (1992) Grading the severity of chronic pain. Pain 50:133-149. doi:10.1016/03043959(92)90154-4

57. Vujasinovic-Stupar N, Radunovic G, Smailji M (2005) Quality of life assessment in osteoporotic patients with and without vertebral fractures. Med Pregl 58:453-458. doi:10.2298/MPNS0510453V

58. Yoshida T (2002) Cases of osteoporotic spinal fracture developing marked vertebral body pressure deformity. Cent Jpn J Orthop Surg Traumatol 45:473-474 